\title{
Viața spirituală și ethosul misionar în închisorile comuniste. Studiu de caz: Închisoarea Târgu-Ocna intre anii 1950-1953
}

\section{Dragoș-Dumitru URSU}

Abstract: At the beginning of the 1950s, the Târgu Ocna sanatorium prison represented a place of spiritual recovery for the prisoners that had passed through the hell of the Pitești re-education. Using the knowledge and the mystical experience gained in the Aiud penitenciary during the Antonescu period (the beginning of the 1940s), prisoners Ioan Ianolide, Valeriu Gafencu and Gheorghe Jimboiu became a focus point of spiritual life for the other prisoners at Târgu Ocna. Solidarity, cultural effervescence and spiritual effort accompanied by the practice of the Prayer of the Heart individualized the prison of Târgu Ocna within the memory of the Romanian Gulag. Using archive sources (individual files from the Archive of the National Council for the Study of the Securitate Archives), along with memoralistic literature, the paper proposes to radiograph the spiritual life of the Târgu Ocna political prisoners within the larger context of spiritual resistance to communism. Transfiguration of suffering, detachment from the political struggle and the complete assumption of the spiritual warfare have defined the „resistance through faith" of the imprisoned. 


\section{Dragoș-Dumitru URSU}

Keywords: Mysticism, Christian mission in communist prisons, the Prayer of the Heart, Valeriu Gafencu, Ioan Ianolide

Închisorile comuniste au fost spații ale (re)descoperirii lui Hristos $^{1}$, în care suferința, foamea, frigul, izolarea, torturile i-au solidarizat pe cei închiși în fața regimului represiv.

Într-un astfel de context, al mizeriei și disperării, aproapele a devenit singurul sprijin în lupta pentru supraviețuire fizică și spirituală. Deținuții, care își asumă pe deplin suferința, devin pentru ceilalți lumini călăuzitoare pe drumul întâlnirii cu Hristos, transformând, totodată, temnițele comuniste în catacombe de mărturisire creștină.

Un asemenea exemplu, reprezentat de activitatea misionară a lui Valeriu Gafencu alături de Ioan Ianolide și Gheorghe Jimboiu în închisoarea - sanatoriu Târgu Ocna, constituie tema acestui studiu.

Formați în cadrul grupului misticilor din temnița Aiudului în perioada 1941-1947, Valeriu Gafencu și Ioan Ianolide aduc cu ei la Târgu Ocna, începând din iunie 1950, un duh de înnoire duhovnicească ce are în centru efortul isihast de dobândire a rugăciunii inimii. Acest efort e documentat cu acribie de Securitate în dosarele sale, fiind asimilat unei activități politice.

„Izvorul” preocupărilor spirituale ale deţinuţilor este identificat de Securitate în persoana lui Ioan Ianolide, considerat liderul grupei ,mistico-religioase”, din care mai fac parte alături de Valeriu Gafencu Aristide Lefa, Gheorghe Jimboiu, Constantin

\footnotetext{
${ }^{1}$ Dragoș Ursu, Martirii temnițelor comuniste intre identitatea creștină și cea politică, în „Eucharist and Martyrdom. From the Ancient Catacombs to the Communist Prisons". Proceedings of the 13th International Symposium of Science, Theology and Arts (ISSTA 2014), Alba Iulia, Edit. Reîntregirea, p. 471. ${ }^{2}$ Arhiva Consiliului Național pentru Studierea Arhivelor Securităţii (ACNSAS), fond Informativ, dosar 233727, vol. 1, f. 163.
} 
Samargescu ${ }^{3}$, Nicolae Grozavu, Constantin Ţoţea, Petre Grigorescu, Iustin Paven, Gheorghe Chelemen ${ }^{4}$ şi care se află în legătură cu deţinuţii Nicolae Itul, Nicolae Țenea, Ion Vălimăreanu, Ion Măcrineanus.

Despre Ianolide informatorii notează că deţinuţii ,îi poartă respect şi întotdeauna vorbesc cu bună stimă de el”, la el venind „ceilalţi legionari şi-i cer sfatul când vor să facă ceva"’, dar mai ales „,este foarte periculos pentru cei din jur", deoarece ,a expus teorii mistice împotriva raţiunii" ".

Poziţia duhovnicească a lui Ianolide se evidenţiază și în raportarea faţă de administraţie: „Iată ce sfaturi le dădea într-o zi în cameră: Conflictele acestea cu administraţia trebuie evitate, $n u$ sunt bune; î pornim contra noastră" ${ }^{10}$.

Atitudinea faţă de conducerea penitenciarului este expresia viziunii generale asupra luptei politice, „,despre care Ianolide Ioan spune că e pe planul al doilea pentru că politica e legată de lumea şi de viaţa de pe pământ - ei urmărind viaţa de dincolo, din cer"11.

Aceste reflecţii redau fidel starea sufletească a lui Ioan Ianolide, responsabil de „popularizarea misticismului religios” şi „care în orice ocazie caută să arate celorlalţi că e păcat să faci rău altcuiva, că e bine să înlături toate pornirile rele, că adevărata viaţă este viaţa viitoare şi alte lucruri de felul acesta prin care caută să

\footnotetext{
${ }^{3}$ Ibidem, f. 170.

${ }^{4}$ Ibidem, f. 163.

${ }^{5}$ Ibidem, f. 166 - verso.

${ }^{6}$ Ibidem, f. 170.

${ }^{7}$ Ibidem, f. 169.

${ }^{8}$ Ibidem, f. 168.

${ }^{9}$ Ibidem, f. 167.

${ }^{10}$ Ibidem, f. 170.

${ }^{11}$ Ibidem, f. 163.
} 


\section{Dragoș-Dumitru URSU}

menţină în această situaţie elementele tinere"12.

Duminica reprezenta un moment de intensificare a preocupărilor spirituale, Ianolide alături de ceilalţi „,mistici” fiind semnalat ,că a cântat în cor cântece religioase din care reţin fraze: Smulgeţi-vă din mijlocul celor răi şi întăriţi oastea creştinească. Au cântat 6-7 cântece în genul acesta creând în cameră o atmosferă de biserică"'13.

Resursele duhovniceşti ale deţinuţilor erau reprezentate de textele evanghelice memorate în integralitate, precum ,predica de pe munte, parabole versificate ca de ex: parabola fiului risipitor"14, alături de Evanghelia Sfântului Ioan, care circula printre deţinuţi ${ }^{15}$.

Influenţa lui Ianolide asupra celorlalţi este menţionată de informator: „Prin discuţiile pe care le are cu diferiţi deţinuţi îi face să creadă orbeşte în divinitate şi în viaţa de dincolo. Are multă putere de convingere. Am asistat la o discuţie unde Ianolide pune întrebarea: «Unde şi cum mă găsiţi pe mine?» Nimeni nu a răspuns. Răspunsul 1-a dat tot el: «În Hristos mă găsiţi şi în rugăciune». Face afirmaţia că el nu trăieşte şi că El (adică Dumnezeu) trăieşte în corpul lui" 16 .

Având ca fundament „credinţa oarbă în divinitate”, Ioan Ianolide le transmite ,ucenicilor” experienţa filocalică de la Aiud. Expunerea detaliată a agentului, datorată pregătirii sale teologice, reprezintă pagini inedite de trăire isihastă în dosarele Securităţii:

„Deţinutul Ianolide Ioan spune că această trăire (misticoreligioasă) se realizează printr-o permanentă încordare a tuturor gândurilor omului la Dumnezeu, că acest exerciţiu trebuie făcut

\footnotetext{
${ }^{12}$ Ibidem, f. 177 - verso.

${ }^{13}$ Ibidem, f. 170.

${ }^{14}$ Ibidem.

${ }^{15}$ Interviu cu Virgil Totoescu, realizat de Dragoș Ursu, 14 august 2010.

${ }^{16}$ ACNSAS, fond Informativ, dosar 233727, vol. 1, f. 169.
} 
timp îndelungat şi că la un moment dat omul ajunge să simtă pe Dumnezeu care coboară deasupra capului său şi îl luminează, şi că din acel moment harul lui Dumnezeu intră în omul respectiv. De asemenea, Ianolide spune că spunând în acest timp în mod permanent anumite rugăciuni scurte ca de ex: Doamne, miluieştemă pe mine păcătosul, omul ajunge să spună apoi această rugăciune în mod automat. În urma acestui exerciţiu omul ajunge să fie permanent însoţit de Dumnezeu şi să nu mai facă păcate, fiind deci un om perfect. Descrierea acestui exerciţiu mi-a fost făcută personal de către Ianolide Ioan.

Practica acestui exerciţiu religios este făcută permanent de legionarii din grupa mistică-religioasă - şi problema aceasta este principală în discuţiile pe care aceşti legionari le au cu ceilalţi deţinuţi din secţie" 17 .

Efortul duhovnicesc impulsionat de „trăirea misticoreligioasă" a transfigurat vieţile deţinuţilor, caracterizările informatorului reflectând nivelul spiritual al acestora:

„Dintre aceşti legionari din grupul mistic, Toţea Constantin este cel mai habotnic. De aceea problemele de care se preocupă acesta sunt în majoritate probleme religioase sau mistic legionare. Toţea Constantin afirmă că în momentul în care va ieşi afară se va face preot şi că pe această cale va putea lupta mai uşor împotriva duşmanilor bisericii şi împotriva comunismului. De aceea, Toţea Constantin, legionar intrat pe linie mistică din 1942 de la închisoarea Aiud, se pregăteşte de pe acum însuşindu-şi cunoştinţele dogmatice şi formele de cult ale bisericii - învăţând pe dinafară slujbe religioase şi texte din biblie"18.

Un alt exemplu este Iustin Paven, care nu a fost condamnat pentru activitate legionară, dar în detenţie îl cunoaşte pe Ioan

${ }^{17}$ Ibidem, f. 163 - verso.

${ }^{18}$ Ibidem, f. 166. 


\section{Dragoș-Dumitru URSU}

Ianolide şi i se alătură acestuia în grupa „mistico-religioasă”.

„Datorită legăturilor pe care le are cu grupul misticlegionar încă de la Tg. Ocna, Paven Justin este un element fanatizat în atitudinea ostilă clasei muncitoare, afirmând că pentru el faptul că stă în închisoare şi că suferă nu poate decât să-1 întărească în convingerile lui şi în lupta pe care o duce. Paven Justin, agitând diferite probleme împotriva gândirii materialiste şi organizării socialiste, spune: «eu sunt unul din aceia care au cunoscut personal toată ticăloşia şi murdăria metodelor de lucru comuniste», deoarece la Piteşti luase atitudine împotriva legionarilor lucrând ca informator. Venind la Tg. Ocna, Paven Justin a dezinformat în faţa legionarilor toate însărcinările ce i-au fost date"19.

"Convertirea” lui Iustin Paven este un rodul dragostei lui Ianolide, care-1 transformă pe acesta din „reeducat” în „mistic”. Experienţa lui Iustin Paven reprezintă argumentul sublim al prezenţei lui Hristos alături de cei închişi, ajutându-i să transfigureze „experimentul diabolic de la Piteşti” în „fenomenul mistic de la Târgu-Ocna". Iustin Paven este exemplu, prin excelenţă, al eşecului reeducării prin tortură care urmărea satanizarea omului. Acelaşi deţinut, care-i demasca la Piteşti pe proprii camarazi, a devenit „,vas ales”, practicant al rugăciunii inimii şi, în cele din urmă, slujitor al lui Hristos ${ }^{20}$.

Jertfa pentru aproapele s-a materializat, alături de sprijinul sufletesc, și prin solidaritatea față de cei aflați în suferință. Astfel, din momentul sosirii grupului de deţinuţi menţionat la Târgu Ocna a început organizarea asistenţei acordată bolnavilor, majoritatea dintre cei închişi fiind diagnosticaţi cu TBC. Îngrijirile acordate erau conduse de medicii-deţinuţi Ghiţulescu, Banu şi Floricel, care

${ }^{19}$ Ibidem, f. 166 - verso.

${ }^{20}$ Nicolae Trifoiu, Studentul Valeriu Gafencu. Sfântul închisorilor: mărturii ale ale camarazilor de suferință, Cluj Napoca, Edit. Napoca Star, 2002, p. 76. 
beneficiau uneori de ajutorul medicului oficial al penitenciarului, Danielescu ${ }^{21}$.

Dosarele Securităţii conţin referiri multiple la activitatea intensă a deţinuţilor în această direcţie. Astfel, Ianolide „,popularizează importanţa ajutorului legionar în alimente pentru deţinuţi grav bolnavi”22, iar Gheorghe Jimboiu „,-a ocupat îndeaproape de aranjarea ajutorului cu unt, marmeladă şi lapte pe care le-au dat deţinuţilor Popescu Ioan, Bălănescu Mihai, Niţescu Gh. şi Constantin Aurel”"23.

Despre solidaritatea dintre deţinuţi îşi aminteşte cu lux de amănunte Nicolae Itul, relatând pe larg ajutorul acordat lui Gheorghe Miulescu ${ }^{24}$, părintelui Gherasim Iscu ${ }^{25}$ şi studentului Traian Maniu. „A mai venit de la Cluj Maniu, un tânăr medic în anul 6, zdrobit în bătaie. A fost bătut peste rinichi şi paralizase de la brâu în jos. Ştiu că l-am adus pe braţe eu cu încă unul. L-am băgat la camera 4. Discutam foarte mult cu el şi aveam grijă de el, săracu'. Eu mă duceam la el şi-l îngrijeam în mod special, că nu

${ }^{21}$ Interviu cu Nicolae Itul, realizat de Dragoș Ursu 23 octombrie 2009.

${ }^{22}$ ACNSAS, fond Informativ, dosar 233727, vol. 1, f. 85.

${ }^{23}$ Ibidem.

${ }^{24}$ Pe Gheorghe Miulescu, Nicolae Itul 1-a cunoscut în închisoarea Jilava. Au fost transferaţi împreună în Piteşti, pentru ca la Târgu Ocna să-i fie alături până în momentul morţii acestuia, pe 28 iulie 1950. Despre ajutorul acordat acestuia îşi aminteşte: „Încă o dată, precizez, îmi luasem obligaţia să ajunez o dată pe săptămână, şi mâncarea o dădeam discret unuia dintre cei slabi, ca să nu mă vadă că ajunez, simulam. Azi luni, săptămâna viitoare marţi, cealaltă miercuri, deci aşa-mi luasem eu obligaţia. Acum, avându-1 lângă mine (pe Gh. Miulescu, n.n.) îi serveam lui masa, era slab, d-abia mergea pe picioare." (Interviu cu Nicolae Itul, 23 octombrie 2009).

${ }^{25}$, ,...] L-am îngrijit pe părintele Iscu, stareţul mânăstirii Tismana, chiar în noaptea aia de Crăciun (părintele Iscu a murit de Crăciunul anului 1951, n.n.), adică nu, cu o noapte înainte am stat cu el de veghe. Câte am povestit şi cu părintele Iscu...” (Interviu cu Nicolae Itul, 30 octombrie 2009). 


\section{Dragoș-Dumitru URSU}

oricine să oferea să stea lângă tuberculoză. Maniu, neputându-se mişca, făcuse escare mari pe spate, carne vie, se dusese toată pielea, carnea, rămăsese o pojghiţă subţire. Eu 1-am dezbrăcat, întorceam omul, îl spălam, îl curăţam. Într-o zi am rugat pe doctoriţă să ne aducă un colac, să pun sub el, ca să nu i se extindă escara. Şi femeia 1-a adus. Altă dată i-am făcut un coviltir din arbuştii din grădină. Şi făcusem un fel de arcuri legate cu aţe, ca să stea cuvertura peste el, să-i ţină cald, n-am avut căldură de sobă. Să-1 pot întoarce acolo, sub coviltirul ăla, se simţea bine"26.

Dacă ar fi să identificăm aspecte ce particularizează închisoarea Târgu Ocna în memoria Gulagului românesc, ne-am putea opri asupra a două episoade legate de personalitatea lui Valeriu Gafencu. Ambele sunt rememorate fidel de către Nicolae Itul. Primul este sacrificiul pe care Gafencu îl face pentru pastorul Richard Wurmbrand, oferindu-i streptomicina salvatoare pe care o primise de la un alt deţinut:

„A fost acolo un băiat, prieten foarte bun, Leonida Stratan, un băiat mic de statură, foarte drăguţ, cuminte, tatăl lui era preot militar. Am stat cu el în cameră. La fereastră era Leonida Stratan, apoi eu, Cezar Tănase, Lefa Aristide. Acest Stratan a avut parcă 7 ani condamnare şi s-a eliberat, dar înainte de eliberare, la Tg. Ocna a primit un pachet. Cum-necum, i s-a aprobat. A fost ofiţerul? $\mathrm{N}-\mathrm{a}$ fost?, i s-au dat medicamentele. Vreo 5 flacoane de streptomicină. Şi Leonida a zis: - I le dau lui Valeriu, să se vindece Valeriu. Şi se hotărâse cu doctorii, a luat medicamentele şi Valeriu a zis: - Daţii-le lui Richard. - Cum mă, dar nu...? - Daţi-i-le lui că eu şi-aşa am să mor. Daţi-i-le lui că poate asta are să vă ajute cu ceva. I leam dat lui Wurmbrand şi Wurmbrand s-a făcut sănătos. I-a lungit viaţa. Wurmbrand s-a eliberat, Valeriu a murit" ${ }^{27}$.

\footnotetext{
${ }^{26}$ Interviu cu Nicolae Itul, realizat de Dragoș Ursu, 30 octombrie 2009.

${ }^{27}$ Ibidem.
} 
Moartea lui Valeriu Gafencu este cel de-al doilea moment referenţial pe care posteritatea $1-a$ păstrat. Descris cu lux de amănunte de către Ioan Ianolide în memoriile sale, acesta ocupă, de asemenea, şi în relatarea lui Nicolae Itul o poziţie primordială. Atitudinea lui Itul şi desfăşurarea evenimentelor din preajma acestui moment se constituie într-o frescă expresivă a microuniversului carceral de la Târgu Ocna, caracterizat de strânsele relaţii dintre deţinuţi.

„[...] Cam după 1 ianuarie mi-a zis Valeriu: - Nicolae, am o rugăminte la tine. - Spune Valea, orice. - Vezi, eu am avut o stare deosebită în care mi s-a spus că în 18 februarie voi pleca la Domnul. - O, Valeriu, dar eşti sigur? - Sunt sigur. - Eu mă-ndoiesc că Dumnezeu ne spune sfârşitul. - Şi totuşi, mie mi l-a spus. Am avut o revelaţie. O oarecare îndoială mi-am păstrat în suflet, mă iertaţi, spun adevărul. - Valea, dacă zici tu, vom vedea. Dar spune ce doreşti. - Te rog pe tine, nu spui nimănui, să pregăteşti hainele cutare, cutare: cămaşă, izmene, batistă, maieu, ciorapi, să fie albe, toate curate. Să faci rost de o lumânare că n-avem lumină în timpul nopţii. - Da, zic, asta e cea mai grea problemă. - Să ai grijă când mor să fii aici lângă mine, în ziua de 18 februarie să fii la mine. [...] Avea o cruciuliţă de argint legată cu aţă. - Asta să mi-o pui in gură pe partea dreaptă, ca eventual dacă voi muri şi voi fi înhumat să mă găsiţi şi să ş̧iţi locul, cum să mă identificaţi. - Promit că fac. - Te aştept, pe măsură ce le realizezi să mi le-arătì”28.

Alături de Ioan Ianolide, Nicolae Itul finalizează pregătirile pentru ziua de 18 februarie. „La ora 10 a venit vizita medicală, doctoriţa însoţită de doi medici (deţinuţi n.n.), Floricel şi Ghiţulescu şi de un miliţian, sergent major, care era sanitar - n-avea voie să fie singură" ${ }^{\prime 2}$. După ce a inspectat starea a trei deţinuţi, printre care şi

\footnotetext{
${ }^{28}$ Ibidem.

${ }^{29}$ Interviu cu Nicolae Itul, 30 octombrie 2009.
} 


\section{Dragoș-Dumitru URSU}

Wurmbrand, „,comisia” a ajuns la patul lui Valeriu Gafencu. Acesta ii mulţumeşte doctoriţei pentru îngrijirea acordată, afirmând încă o dată iminenta „trecere" ${ }^{30}$. Cu ultimele puteri, muribundul le mulţumeşte şi medicilor-deţinuţi care au avut grijă de el: - Vă mulţumesc şi vouă camarazilor doctori pentru tot ce-aţi făcut, in numele tuturor. Purtaţi-vă frumos, rugaţi-vă lui Dumnezeu să ajungem toţi în acelaşi loc" 31 .

Ioan Ianolide completează mărturia lui Nicolae Itul, detaliind ultimele cuvinte ale lui Valeriu Gafencu: „Sunt fericit să mor pentru Hristos. Eu plec, dar vor aveţi de purtat o cruce grea şi o misiune sfântă. Îndrăzniţi şi rugaţi-vă! Păziţi neschimbat adevărul, dar să ocoliţi fanatismul. Ateismul va fi învins, dar să fiţi atenţi cu ce va fi înlocuit. Ioane, să duceţi duhul mai departe! Aici a lucrat Dumnezeu!" 32 .

Valeriu Gafencu, Ioan Ianolide și cei din jurul lor, cunoscuți ca făcând parte din „grupul misticilor”, au fost păstrați în memorie, în primul rând, pentru activitatea lor spirituală și misionară din închisoarea Târgu Ocna. La începutul anilor 50, încercarea de transfer al ,reeducării” de la Pitești în închisoarea Târgu Ocna a eșuat datorită răspunsului dat de deținuții aflați aici: dragostea lor față de aproapele, concretizată în ajutorul material și susținerea spirituală a aproapelui creionează doar unul din numeroasele tablouri ale misiunii creștine în închisorile comuniste.

${ }^{30}$ „Doamna doctor, vă mulţumesc din tot sufletul meu că v-aţi purtat ca o mamă pentru copii, aţi făcut tot efortul. Acum eu sunt pe cale de a pleca de aici..." (Interviu cu Itul Nicolae, 30 octombrie 2009).

${ }^{31}$ Interviu cu Nicolae Itul, 30 octombrie 2009.

${ }^{32}$ Ioan Ianolide, Întoarcerea la Hristos: document pentru o lume nouă, București, Edit. Christiana, 2006, p. 189. 


\section{Bibliografie}

1. Arhiva Consiliului Național pentru Studierea Arhivelor Securității (CNSAS), fond Informativ, dosar 233727.

2. Interviu cu Virgil Totoescu, realizat de Dragoș Ursu, 14 august 2010.

3. Interviu cu Nicolae Itul, realizat de Dragoș Ursu, 23 octombrie 2009.

4. Interviu cu Nicolae Itul, realizat de Dragoș Ursu, 30 octombrie 2009.

5. Ianolide, Ioan, Intoarcerea la Hristos: document pentru o lume nouă, București, Edit. Christiana, 2006.

6. Trifoiu, Nicolae, Studentul Valeriu Gafencu. Sfântul închisorilor: mărturii ale camarazilor de suferință, Cluj Napoca, Edit. Napoca Star, 2002. 